Keen, B., \& Gainsbury, S. M. (2021). Perceptions of young adults' problematic technology use among Australian youth professionals. Cyberpsychology: Journal of Psychosocial Research on Cyberspace, 15(1), article 8.

https://doi.org/10.5817/CP2021-1-8

\title{
Perceptions of Young Adults' Problematic Technology Use Among Australian Youth Professionals
}

\author{
Brittany Keen \& Sally M. Gainsbury \\ School of Psychology, Faculty of Science, The University of Sydney, Sydney, Australia
}

\begin{abstract}
The effects of excessive and problematic technology use on young people's mental health has not been explored from the perspective of those who work closely with youth in a professional capacity. This study reports on findings from focus group interviews with 22 professionals in the fields of education, counselling and mental health, community and housing, social work, and drug and alcohol services. Most problems participants observed related to video gaming (predominantly amongst men) and social media use (predominantly amongst women). Participants perceived most harms to be related to social or psychological difficulties such as relationship breakdowns, isolation, low self-confidence, depressive symptoms, and unrealistic expectations of success. More tangible harms relating to homelessness, physical fighting resulting from online exclusion, and sleep disturbances leading to absence from school and work commitments were also reported, albeit less frequently. The relationship between technology use and poor psychosocial outcomes was conceptualised as being complex and often cyclic in nature, whereby disadvantage and family dynamics were often predictive of problems. Most services did not formally screen for technology-related problems, however many were interested in upskilling by way of training, awareness, and implementation of screening measures and formal referral procedures. This research suggests that young people are presenting with technology-related problems but that more needs to be done to provide youth services and organisations with adequate support to identify and assist with these issues.
\end{abstract}

Keywords: Video gaming; social media; online; technology-related problems; mental health; youth; young adults

\section{Introduction}

Increased access to online technologies has resulted in the integration of digital devices into everyday life. Most Australians have access to the Internet via multiple devices such as mobile phones, tablets, and computers, and Internet use is highest amongst those aged 15-17 (98\% of this age group; Australian Bureau of Statistics, 2018). Personal access to digital technologies has resulted in substantial improvements to our health and wellbeing (Buntin et al., 2011; Goldzweig et al., 2009; Pittman \& Reich, 2016; Valkenburg et al., 2006). However, concerns have been raised with regards to the amount of time spent in front of screens and the potential negative effects on mental and physical health, particularly for young people (Boers et al., 2019; Kremer et al., 2014; Maras et al., 2015). The World Health Organisation (WHO) released recommendations for limited screen time for children, with concerns that excessive amounts of time spent on devices may impede psychological and social development (WHO, 2019b).

Accordingly, there is increasing recognition of problematic engagement or excessive use of different online activities and digital devices which appear to share many similarities with behavioural (non-substance) addictions. 
Gambling Disorder and Gaming Disorder constitute two recognised technology-related behavioural addictions (American Psychiatric Association, 2013; WHO, 2019a). Substance and behavioural addictions share characteristics including preoccupation and difficulty controlling the behaviour leading to marked subsequent distress and impairment to social and occupational functioning (Grant et al., 2010).

Individuals are presenting to mental health services seeking treatment for technology-related additive behaviours, however there is a significant treatment gap whereby health professionals do not feel confident treating issues around problematic technology use (King et al., 2012; King \& Delfabbro, 2019; Loh et al., 2016; Torres-Rodríguez et al., 2018). Research has not comprehensively identified the prevalence, severity, and nature of the harms from excessive technology use in terms of young people's mental health and its impacts on broader community services.

We aimed to address this gap by developing foundational work on the harms associated with problematic and excessive use of digital technologies as seen through the lens of youth professionals. This research stands as a necessary first step in gathering evidence from youth professionals on the negative correlates of excessive technology use among young people. Currently, it is not clear if youth services are screening for technology-related problems, if there are any standard procedures in place to respond to identification of problems, and what resources are necessary to assist professionals on this matter. As such, a further aim was to report on youth services' procedures for identifying and responding to technology-related problems.

\section{Background}

Several para-addictive behaviours involving technology have been proposed for further research and consideration as clinical disorders. Internet addiction, smartphone addiction, and social networking site addiction have all been proposed for investigation as potential new disorders. Such behaviours have been associated with psychological distress and poor self-care; however, there is insufficient evidence to suggests they qualify as mental disorders (Kuss et al., 2014; Kuss \& Griffiths, 2011; McNicol \& Thorsteinsson, 2017; Petry et al., 2018; Pontes, 2017; Pontes \& Griffiths, 2017; Sohn et al., 2019).

With the exception of regulated activities such as online gambling, minors are typically not prohibited from engaging in most online activities, and online gaming and social media use are common (J. E. Brand et al., 2017). Prevalence studies investigating Internet Gaming Disorder (IGD) have typically focused on adolescents and young adults and demonstrated higher rates of disorder prevalence amongst younger gamers compared to adults (Fam, 2018; Mentzoni et al., 2011). About one-third of adolescents play free-to-play simulated gambling games which do not require age restrictions (Ipsos MORI, 2011; Keen, 2019; King et al., 2014). Free-to-play games produce more winning outcomes than for-profit gambling games and may encourage young people to develop unrealistic and problematic expectations of wining in commercial gambling (Gainsbury et al., 2016; King et al., 2014).

Academics have recommended a more nuanced approach to studying technology-related behavioural addictions due to the interaction between clinical symptoms and device feedback (Kardefelt-Winther, 2014a; Weinstein et al., 2017). Existing theoretical models of IGD suggest a complex interplay of affective, cognitive and behavioural variables involved in disorder development (M. Brand et al., 2014; Dong \& Potenza, 2014; King \& Delfabbro, 2014). More broadly, scholars have argued that general technology-related behavioural addictions may be better conceptualised as compensatory behaviours that serve a functional purpose for those experiencing mental health problems (Kardefelt-Winther, 2014a). The compensatory model is supported by evidence that problem symptoms tend to differ between technological activities, suggesting each activity may serve a different and central function (Baggio et al., 2018; Mitchell et al., 2011).

A small number of studies implicate psychological wellbeing as a mediational variable in the development of technology-related problems. Avoidance-based coping strategies were found to partially mediate the relationship between low self-esteem and Internet Addiction in a sample of young adults in Italy (Servidio et al., 2018). Laier et al. (2018) found that avoidance-based coping mediated the relationship between maladaptive personality traits and IGD. King et al. (2013) found high comorbid depression and anxiety disorders amongst adolescent pathological technology users, however contrary to the aforementioned studies, using technology as an escape was not found to predict pathological use (King et al., 2013). 
Adolescents and young adults may represent a vulnerable population of interest for technology-related problems as they are 'digital natives' - having grown up in the digital age (as compared to those who have adjusted to technological developments; Zenios \& Ioannou, 2018). Adolescence and early adulthood is marked with experimentation in a range of risky behaviours such as alcohol and drug use (Echazu \& Nocetti, 2019) and threequarters of all lifetime mental disorders will start by our mid-20s (Kessler et al., 2007). Technology-related problems may sit appropriately with other risk-taking behaviours during adolescence and early adulthood as young people face increased social pressures to adhere to social norms, and experience identity confusion and parental conflict, which may contribute to the development of technology-related problems around this age (Echazu \& Nocetti, 2019; González-Bueso et al., 2018; Shek et al., 2018; Siomos et al., 2012; Venkatesh et al., 2019).

\section{Aims and Objectives}

The purpose of this research was to catalogue the negative consequences associated with problematic and excessive technology use in terms of young people's (aged 17-24) mental health, and to document the gaps in services' procedures for identifying and assisting young people experiencing technology-related problems. Technology is changing at a rapid rate and so the problems associated with it are likely to evolve at a commensurate pace. Little work has been carried out investigating the perspectives of individuals who have regular and direct contact with young people in a professional capacity in the community. Professionals who work within the youth sector have valuable insight into the types of issues young people seek assistance for and are able to comment on changing trends in demand for mental health assistance over time. This research is an important first step to determine what resources youth professionals may need to address problems so they are prepared when individuals seek help. Measuring harm is crucial to informing appropriate treatment approaches as well as advising funding bodies about provision of adequate services, and regulators about important policy recommendations. Participants were not asked to discuss benefits associated with technology use, and so the results of this study represent a biased literature toward problematic technology use and should not be considered generalisable to the majority of young people who engage with digital device and online activities. Problems not directly related to problematic excessive use (e.g., problematic but not excessive behaviours such as sexting, cyber-bullying, etc.) were excluded from the discussion.

\section{Operational Definition of Outcome Variable}

Consistent with similar research (e.g., Shapira et al., 2003), we defined technology-related problems as characterised by a pattern of persistent and excessive use and leading to poor mental health outcomes and significant impairment and/or distress. Online technologies were defined for participants before the focus group as: social networking sites and their associated instant messaging apps (e.g., Facebook, Instagram, Snapchat, etc.), video games, simulated and traditional forms of gambling (e.g., loot boxes, skins betting, e-sports betting, virtual casinos, online gambling), which can be accessed by various digital devices such as mobile phones, tablets, computers, smart TVs, and gaming consoles.

\section{Methods}

\section{Participants}

Focus group participants were professionals recruited through local youth and community services and organisations using a convenience sampling method. Participants were eligible to take part if they worked in organisations that provided community, health, social or educational services to young people between the ages of 17-24. Participants were recruited via existing professional networks, as well as via emails to relevant organisations with no prior relationship. To ensure diversity in responses across a range of organisations, we targeted professionals across the fields of community, crisis support, homelessness, medical, justice, mental health, education, and faith. Data collection took place between September and December 2019. 


\section{Measures}

Participants were informed that they would take part in a discussion around young people's problematic use of various forms of technology and were provided the aforementioned operational definition before the focus group began.

There were three primary research questions which oriented the focus group discussions:

1. What kind of problems do youth service workers see in their roles with regards to young people's use of various forms of online technology and digital devices?

a. What are the specific nature and severity of harms reported by those who access youth services?

b. Do problems differ by the form of technology engaged in, or are problems more likely to be reported by any specific cohort or related to any personal characteristics or behaviour?

2. Do services currently screen for technology-related problems, and if so:

a. How are these screening measures implemented?

b. What procedures are in place following positive screening or observation of problems? (E.g., referrals, treatment etc).

3. What kind of resources do youth service workers currently have (or need) to be able to adequately address technology-related problems?

\section{Procedure}

Potential participants were recruited through telephone and email contact with youth organisations, via social networking sites, and via existing relationships. Consenting participants $(N=22)$ took part in four separate faceto-face focus groups (4-6 per group) which involved a one-hour discussion around the impacts of problematic technology use on young people's mental health. Participants were asked open ended questions and probing around the aforementioned research questions. Three of the focus groups were led by the lead author and the other by a postdoctoral researcher working alongside the authors (this was necessary as two groups ran concurrently due to participant scheduling). The focus group moderator was responsible for ensuring all participants had equal opportunity to answer all questions (i.e., that some members were not answering all questions while others remained silent). This was ensured by regularly checking in with 'quiet' members of the group and interjecting and redirecting where necessary with overly talkative members of the group.

Informed consent was obtained from all participants, and the study was approved by the University of Sydney Human Research and Ethics Committee in accordance with the Declaration of Helsinki.

\section{Analytical Approach}

This study used a combination of inductive and deductive approaches to the qualitative analysis of the focus group data. The research questions in part guided the structure of the interviews and provided the overall framework for the analysis (deductive). However, it was important to provide space that allowed participants to contribute their own perspectives on the issue in order to generate unexpected lines of reasoning and research (inductive).

The research questions above guided content analyses to reduce, synthesise and quantify the data to develop a preliminary conceptualisation of difficulties experienced by young adults as a result of problematic engagement with digital technologies. Frequencies of identified technological activities and associated problems were calculated in order to determine what problems were observed most, and if these were disproportionately reported in association with some forms of technology compared to others. In this sense the analysis involved both qualitative and the more traditional quantitative form of content analysis (Schreier, 2014). The purpose of using this approach was that a foundational catalogue of technology-related problems experienced by young adults could begin to be documented by the data gathered, which future empirical studies can build on and test using confirmatory methods.

Analysis of the transcribed discussions followed the steps outlined by Schreier (2014). An analysis procedure as well as the final coding frame can be found in Supplementary Material A. All data was coded using NVivo12 and 
frequency counts were calculated using a combination of NVivo queries and Microsoft Excel formulas. A second researcher applied the initial coding frame to one-quarter of the focus group data. There was substantial overall agreement between coders in the test coding phase $(\kappa=0.78)$ (Viera \& Garrett, 2005). Areas of lower agreement $(\mathrm{k}<0.60)$ were typically found in specific sub-categories of larger themes (e.g., social media problems). Low agreement was investigated, disagreements discussed, and the coding frame adapted accordingly for the remaining main analysis.

\section{Results}

\section{Demographics}

Twenty-two professionals participated in the focus groups. Twenty-one (21) participants provided demographic information which is displayed in Table 1.

Table 1. Sample Demographic Details.

\begin{tabular}{lcccc}
\hline & Range & $\boldsymbol{M}(\boldsymbol{S D})$ & $\boldsymbol{N}$ & Valid \% \\
\hline Gender & & & 10 & $(47.62 \%)$ \\
$\quad$ Male & & & 11 & $(52.38 \%)$ \\
$\quad$ Female & $25-57$ & $39.29(10.28)$ & & \\
Age & $0.17-24$ & $8.5(6.84)$ & & \\
Years worked as youth professional & & & \\
Organisation type & & 6 & $(28.57 \%)$ \\
$\quad$ Community (housing) & & 7 & $(33.33 \%)$ \\
$\quad$ Counselling and mental health & & 3 & $(14.29 \%)$ \\
$\quad$ Education (Secondary schooling) & & 4 & $(19.05 \%)$ \\
$\quad$ Social work & & 1 & $(4.76 \%)$ \\
$\quad$ Drug and alcohol & & & & \\
\hline
\end{tabular}

\section{Quantitative Content Analysis Results}

Technology-related problems were reportedly related to three types of activities of interest; gaming, social media, and gambling. How often each activity was mentioned was determined by a three-step process using NVivo 12 . First, during the coding phase, authors specifically coded any mention of an online or device-based activity as "tech activity". Following this, a word frequency query was run within the "tech activity" node, which returned 22 terms or phrases (e.g., "playstation", "snapping", "casino", "gamer"). These terms or phrases were subsequently collapsed into three meaningful and logical categories (gaming, social media, gambling). Last, to ensure we had conducted an exhaustive search of all phrases including any derivatives of the words, three specific text search queries were carried out to search for words or phrases mentioned in the transcripts that fell under each of these categories (i.e., social media text search terms: "social media OR instagram OR snap chat OR snapchat OR facebook"). Any new phrases in the transcript that were not already coded at the "tech activity" node were coded and the word frequency was re-run returning the same 22 phrases and associated frequency of mentions.

Phrases relating to video gaming were mentioned the most throughout the focus groups $(43.81 \%)$ followed by social media (38.73\%) and then gambling (17.46\%). Most problems were conceptualised as effecting young adults' physiological, psychological, social, or educational and vocational wellbeing. Despite the interviewer focusing on mental health outcomes, participants referenced social problems such as isolation and unhealthy relationships most commonly (108 times), followed by psychological issues such as depression, issues of self-image and selfconfidence and being constantly stimulated by digital technology (89 times), physical problems such as disturbances to sleep habits and reduced physical activity were mentioned 31 times, and problems at work or school were mentioned the least (17 times) (Figure 1). 
Figure 1. Hierarchical Treemap Illustrating the Relative Frequency of Types of Technology-Related Problems.

Types of Technology-related problems

" Physiological "Psychological " Social " Educational and vocational

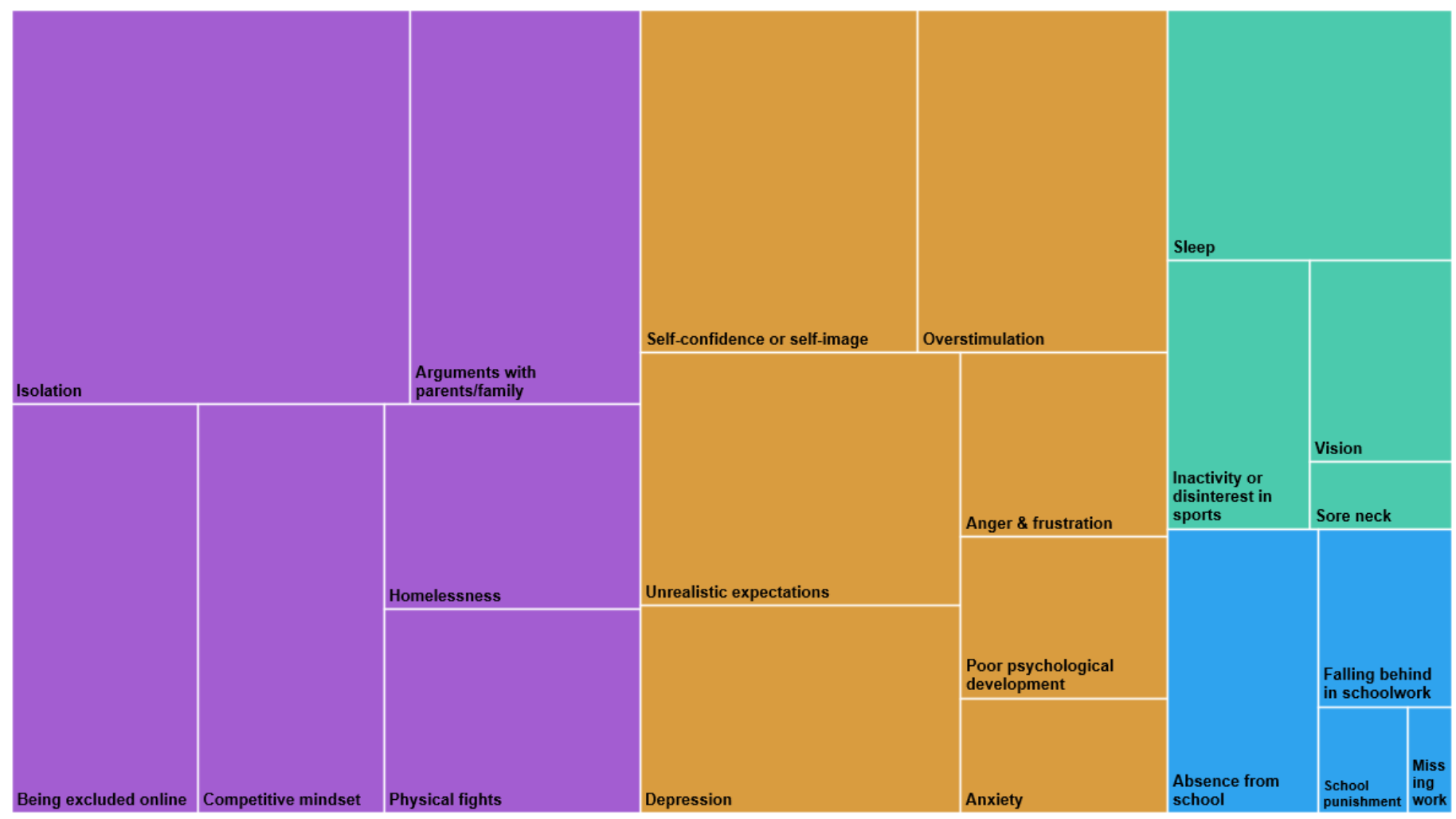

Note. The size of the squares is proportionate to the frequency with which those types of harms were mentioned by participants.

\section{Qualitative Content Analysis Results}

Consistent with the guided research questions, participants' responses involved discussions around five central themes: 1) Types of technology-related problems, 2) Typologies of problematic technology users, 3) Direction of causality between mental health problems and technology-related problems, 4) Current awareness, record keeping, and management of technology-related problems, and 5) Recommended resources for service providers. Many sub-themes were identified within these categories and are detailed below with substantiating quotes.

\section{Types of Technology-Related Problems}

Broad technology-related problems were broken down into social, psychological, physiological, and educational and vocational harms. The frequency with which these harms were reported by participants is illustrated in Figure 1. Within each of these categories it was clear that some problems were specifically related to engagement with particular types of activities.

Social. The most frequently reported social consequences of problematic technology use related to a lack of meaningful connection with peers and family members. This was problematic for frontline staff trying to engage young people in crisis accommodation centres.

"They're really distancing themselves from, from the staff... And from other people there, just playing on their phone." (Manager, Homelessness service)

However, an online presence was deemed as necessary to maintain social relevance; absence from the online world was also construed as a form of isolation.

“They [parents] just go, 'Oh [go] outside and enjoy the day!' It's like, 'What are you talking about, I'm isolated if I don't, if I can't contact my friends online, I will lose friends."' (Psychologist) 
Participants reported added pressure for young adults to keep up with social norms and in-group jokes online. Those who were less socially adept in general were reported to suffer worse - as they were often criticised in faceto-face situations and online.

“They find that they're being kind of socially isolated or bullied in the online format, as well as in the face to face format, and because they post the wrong meme, or they say something at the wrong time, you're not keeping up with those... online rules." (Mental Health Clinician)

Problematic gaming was distinctly seen as fostering competition rather than collaboration between peers.

"They have that fear of missing out that, that, you know, everything is raced and then, this is spent [sic] lots of hours investing in it." (Youth Worker)

Participants reported incidents where young men who played online games together had excluded one another online which subsequently resulted in physical fights.

School counsellor: "I think on a few occasions um, some of my boys have come in and said that fights have been as a result of communicating online... physical fights."

Head teacher, Physical education: "So they've found out... from the profile who it is, so that person has eliminated them from the game, which has caused them [social] withdrawals, because then they're not in that circle... and then that's escalated outside."

Parental conflict and disruptions to family life were among the social implications observed by youth professionals.

"So young people will be wanting to use technology to a certain extent, it doesn't match what their parents want them to use, so basically that leads to conflict, fighting... and will lead to us having to intervene." (Mental Health Clinician)

Psychological. Participants reported several factors contributing to poor mental health outcomes for young people experiencing technology-related problems. Many participants referenced issues of self-confidence or selfimage among young people as a result of engaging with their peers online on social networking sites such as Facebook, Instagram, or SnapChat. Image-based platforms such as SnapChat ('Snap') or Instagram ('Insta') were described as most problematic in terms of contributing to body image issues and low self-esteem. Social media was more specifically associated with negative emotions of embarrassment or shame.

"[females] actually report themselves, 'Look, I think I spend too much time on Instagram looking at these models, and it makes me feel crap."' (Mental Health Clinician)

Anger and frustration were reportedly experienced by young people often as a result of restrictions on access to devices by parents, most commonly associated with gaming.

"A lot of anger related video game playing." (Mental Health Clinician)

"It also seems to have a big impact on the young person and parent relationship because it becomes so much of the focus of what they're talking about, it's, 'Get off the games' or, 'I'm going to take your devices from you', and there's this huge angry outburst most of the time, because that's, they say, 'That's my only outlet, that's how I cope..."' (Psychologist)

Participants raised concerns that young adults were constantly overstimulated by 24-hour access to technology connecting them with their peers in a constantly competitive environment. Participants reported that even after removing themselves physically from real-life negative social events (such as bullying at school), young adults had little reprieve as the day's events were continually rehashed online. 
“Now it's constant because it's, how many followers, how many followers have you got, how many likes have you got?" (Youth Officer, Support Work)

Similarly, there was a concern that young adults were being exposed to unrealistic expectations online which would inevitably lead to disappointment and frustration when such high standards were not met. Some participants described this as an "inability to accept failure" and that because the online world is often biased to present the best version of ourselves, young people were not adequately exposed to the normal experiences of failing or being comfortable with being 'average'. Some participants suggested that it was important to encourage young adults to be critical of information online and that many positive images of their peers were not necessarily an accurate representation of their lives.

"There's this continual need to try and impress and, and create this, this almost an avatar of, of your real life so you can keep up with your peers, it's like an extension of the playground" (Youth Officer, Support work)

Teachers were cognisant that many of their students had unrealistic expectations of the ease with which they could become professional gamers.

"Well we've got quite a few kids that are actually thinking about not continuing their education because they think they're going to be this great...gaming entrepreneurs or gamers... They're not really knowing what to do and they're just spending quite a lot of time because they think, 'If I create a next video, somehow along the line it's going to be a hit and I'm going to be a millionaire overnight."' (School Chaplain/Youth Worker)

Educational and Vocational. Participants observed young people's absence from important commitments such as school, court hearings, or work due to high levels of engagement with digital technologies (predominantly gaming).

"I've had three new referrals over the last month that have been like that, the young, young um, twelveyear old's... Won't go to school because uh, they just sit at home gaming." (Adolescent and Family Support Worker, Community Outreach)

For disadvantaged youth, missing important appointments had flow-on effects that had the potential to create further disadvantage.

"They unable to go out there and then access the normal life, daily life routine, to attend their appointment, to attend centre link appointment, job search things like that, and then they end up being left with no money" (Team Leader, Crisis Support)

Physical. Participants raised issues of physical issues such as sleep disturbances, inactivity, and exhaustion resulting from excessive time spent on digital devices.

“They are very tired when they get to school, because they've been online till really late at night, um their parents aren't monitoring them, or they can't monitor them, they've got their phones with them in their bedrooms, their computers, so it's just really easily accessible." (Adolescent and Family Support Worker, Community Outreach)

As a result of late nights online, education staff reported that many students were exhausted during the day, would fall asleep in class, arrive late, or not attend at all.

"What it means is it's disengagement from school, so the fact that they're not sleeping, they're not wanting to come, and so school refusal, which leads to the whole, you know heap of different things..." (School Counsellor) 
Several participants reported that as a result of technology use, many young adults begin to lose interest in sports that they used to enjoy and the sedentary nature of using devices typically contributes to poor physical health.

"They lose, lack of interest in class, sleeping, not participating in sports as regularly, so that comes out there, eating habits are changed, their body weight has changed..." (Head Teacher, Physical Education)

\section{Typologies of Problematic Technology Users}

When asked if there were certain types of people who were more likely to engage with technology at a problematic level; responses were mixed. Some participants suggested that younger children were more vulnerable because they were yet to develop adequate critical thinking skills and a more genuine sense of self.

“The younger they obsess with it, I don't know if that's particularly your age group, but like what we're seeing is, yeah I think that the younger ones don't have it, um, they're not very good at navigating it." (Psychologist)

"I feel like as people get older they gain a bit more perspective and understanding on the fact that Instagram is all just a bit of a, everyone puts on the, the most positive, shows their most positive aspects of their lives..." (Psychologist)

As young adults grow older and engage in society more through stable employment and relationships, some participants described them as less likely to have problems associated with technology use.

"I guess it's because social media is such a strong focus for younger adolescents, I don't know if the older ones mention it as much because, they also have other stuff, like they're at work, they're socialising, they're at uni..." (Psychologist)

Whereas other participants suggested that although many children engaged in excessive technology use, most 'aged-out' of this behaviour by young adulthood, and those who do not are likely to suffer from severe harms around the age of young adulthood.

"I don't know whether it's because supervision at that time drops off, or parents sort of wash their hands from it at that particular time but, um we've had several boys that just don't come to school anymore, and we've let them go because they're over seventeen and they don't seem interested in their... education." (School counsellor)

There appeared to be reasonable agreement in terms of a gender divide with young women being more likely to suffer harms related to excessive social media use and young men were more likely to suffer harms resulting from excessive gaming. Participants depicted young men with gaming problems who suffered with anxiety and anger issues, and adolescent girls who suffered from body image issues associated with problematic social media use. In addition to these typologies, psychologists explicitly suggested the clients they see with Autistic Spectrum Disorder (ASD) symptoms were more likely to suffer from gaming problems compared to any other type of technology use due to the functionality and reward structure of game play.

"[ASD clients get]...fixated on things and so that's a great thing to get fixated on and they can hold their attention, they don't have that craving as much for social connectedness as other people do necessarily... and so they're more than happy to sit online for eight hours, whereas other kids might want to chat to their mates in person and stuff, but ASD kids don't..." (Psychologist)

Clients with Borderline Personality Disorder (BPD) symptoms (Cluster B) were reportedly inclined to seek out social connections and comparisons via social networking sites where they would often report self-harming behaviour in order to receive necessary recognition of their pain from peers. 
"I find that young people with risk issues, or suicidal behaviours... young people with borderline personality traits, are finding it as a platform to kind of seek attention from their friends, or get validated in a certain way." (Psychologist)

\section{Direction of Causality Between Mental Health and Technology-Related Problems}

Most participants agreed that different types of technologies serve a functional purpose for young people. However, participants suggested that when young people suffer undue stress, this functionality sometimes becomes maladaptive and causes problems.

"Like the video game behaviour was something that might have been balanced or pre-existing and not problematic, then because of external influences it became problematic." (Youth Worker, Support Work)

Many participants suggested that it was rare that excessive technology use would occur in isolation and that there was almost always other problems in a young person's life contributing to their impaired wellbeing.

"I've noticed that a young person that plays a lot of video games to cope with whatever's going on in their life, if they come to a difficult time in their life, they'll play more video games, but someone who's never played video games will cope in a different way..." (Youth Worker, Support Work)

One psychologist interviewed felt strongly about how technology-related problems should be conceptualised.

"I've never looked at a situation and gone this kid has a plain old primary addiction...to this stuff. It's not even the chicken or the egg, it's other stuff, and then the problematic use of devices... is always a by-product or an indicator, or like a symptom of something bigger going on, rather than the other way around. I feel super strongly about it." (Psychologist)

Young adults' socioeconomic situation in addition to their family life was discussed as key in determining whether a young person would develop problems with technology use.

"It kind of stands with how vulnerable that a particular student is, and what supports they have going on in their life, if you're coming from a pretty good, stable upbringing... it might be a minor effects... but I think if you come from um an upbringing where there's not much family supports around, you're so entrenched in whatever device you are on, that you're not communicating at all with anybody... um then they might be a bit more severe, the mental health impacts." (School Counsellor)

\section{Awareness, Record Keeping, and Management of Technology-Related Problems}

When asked how participants are typically made aware of technology-related problems, it was apparent that most organisations did not have formal procedures for screening or identifying these types of issues. For participants who worked one-on-one with young adults, problems usually came to light through rapport-building and informal discussions around their daily life. Only one mental health service for young adults specifically screened for problematic technology use.

"[I] think our screening could be better, but the way we identify it is kind of a bit roundabout, like if I identify it will be kind of connecting the dots between you know, maybe they're having financial issues, or different kinds of mental health issues, and once we kind of formulate what's going on there, might point towards a video game problem or a gambling problem." (Senior Services Manager, Homelessness)

For schools and psychologists, parents primarily raised issues of problematic technology use. Community services received this information from parents and schools. Psychologists often found parents contributed to panic surrounding technology use and endorsed an addiction-focused narrative. 
“The young person sees it as a way of coping actually. I've... a kid with kind of a history of trauma and... actually she said that to me... 'I didn't have a problem' but, yeah, parents would be the ones to say, 'Oh I think he's [sic] addicted to gaming."' (Psychologist)

Formal records of incidence of problematic technology use were only kept as part of routine case notes.

"And then, uh [participant] is a school counsellor in a more formal sense. Um I guess for the rest of us it's just sort of the notes that we're keeping in the event that we have to end up speaking to parents about maybe changing habits at home." (Deputy Principal)

With regards to treatment and management of technology-related problems, most organisations referred young adults to external services such as psychologists to treat their problems.

"I'd say we potentially refer them to counsellors." (Youth Worker, Support Work)

Psychologists tended to focus on treating underlying issues which contributed to the problems, rather than the technology use itself.

"Never have I made the focus of treatment about the social media or gaming use... there'll be some talk about limit setting... but I would say the main target that improves the addiction, um or the excessive use is building relationships, either within the family, other peer relationships, reengaging in school, and then the excessive technology use tends to be less, much less of an issue." (Psychologist)

Other non-specialist service providers who attempted to assist young people with technology-related problems did not use specialised treatments, rather they reported altering existing approaches for other psychological or behavioural problems and tailoring them to target technology use. This typically involved a behavioural management plan or contract where setting limits around device use was a key focus.

"You can make a case plan, if they want to reduce their time on the, phone or whatever they're doing, and then you can find out strategies on what to do, so, what's another thing you can do during that time?" (Youth Worker, Support Work)

\section{Recommended Resources for Service Providers}

Most community services and the school staff expressed that they were generally under-funded and under-staffed and that many employees did not have the capacity to provide specialised treatment.

"And there's nothing, we don't know what to do... there's no specialist service working with that sort of stuff so, everyone probably just does their best to, to work through it... The best way they can." (Youth Worker, Support Work)

Many front-line youth workers expressed interest in upskilling and suggested screening tools may be a helpful way to determine if an individual is engaging with technology at problematic levels.

"We don't have expertise... and it's more like incidental, um you know knowledge or those short conversations and I'm sure we can do a lot more and we want to do a lot more." (Youth Worker, Support Work)

"The screening tools is very important knowing when it is to come in at a problem... because some kids... can play well and even make money out of this stuff, so... an understanding for the workers in, in that sort of training, understanding what the new technology is like." (Program Coordinator, Community Education)

In addition to educating professionals, participant suggested community education for parents and children so that early intervention can take place and prevent the onset of more severe problems. 
"Educate the workers, the professionals, but also as a preventative early intervention measure, the young people and at a younger age." (Children and Families Development Officer)

In order to do these things, services expressed a need for greater funding. Service providers explained that they are often funded to carry out specific deliverables, and that deviation from their existing funded responsibilities is difficult.

"We keep trying to do the role of lots of other things... you know we're not, we have to be doctors and nurses and anything else in between here you know?" (Deputy Principal)

\section{Discussion}

The purpose of this study was to detail the nature of technology-related problems amongst young adults and determine what resources youth professionals need to address such issues. Technology-related problems associated with video gaming and social media activities were described most frequently by participants. Most problems were described as relating to a breakdown of relationships between young adults, their peers and parents. Technology use was described as problematic for young people who experienced existing mental health conditions or socioeconomic disadvantage and engaged with technology as a means of coping or gaining unmet needs. Most youth services did not have formal procedures for identifying or treating individuals suffering from technology-related problems. Referrals to external services such as private psychologists were common as many services did not have capacity to expand their services to incorporate specific treatments for technology-related problems.

\section{Perceptions of How Problematic Technology Use Effects Mental Health}

Clinical mental disorders like depression and anxiety were not described extensively as resulting from technology use. Instead, participants tended to discuss the specific mindset or psychosocial symptoms of engaging with technology at a problematic level. These related to feelings of isolation, overstimulation, social exclusion, low selfconfidence, and high social standards or expectations and competition between peers. This is consistent with findings that the impact of social media use on psychological distress is multifaceted (Keles et al., 2020). Similarly, a recent systematic review found that issues relating to emotional health were more common consequences of problematic smartphone use compared to physical health issues (Busch \& McCarthy, 2021). This study adds important qualitative data to the field as most studies are quantitative and based on self-report rather than perceptions of harms from others (Busch \& McCarthy, 2021).

Participants who worked in the education system described how students often spent their nights gaming or on their mobile phones which affected their quality of sleep and by proxy, their attendance and performance at school. This observation is consistent with prior research suggesting heavy technology use is associated with poor sleep quality and lower school attendance, performance, and satisfaction (Rehbein et al., 2015; Vernon, 2016). Schools may be well-positioned to detect early signs of technology-related problems by screening for use when addressing issues of attendance and performance. Similarly, time spent on devices was associated with a decreased interest in previous sporting activities and sedentary behaviour. Inactivity was described as having further repercussions for young people's mental health, which is consistent with literature suggesting regular physical activity may act as a protective buffer against youth mental illnesses (Pascoe et al., 2020).

From their observations, participants expressed that young adults rarely experienced technology-related problems solely, and that comorbid psychological, social, or behavioural problems were often present. This is consistent with previous research which has suggested that comorbid mental health problems are common for those experiencing technology-related problems (King et al., 2013; Latinsky \& Ueno, 2021; Lorains et al., 2011).

Although many participants used the term 'addicted', when describing how young people interacted with technology, many appeared to reject the idea that the technology use itself was creating the problems young people were presenting to them with. This is aligned with other qualitative research suggesting psychologists find terms such as "Internet abuse" unhelpful in the case of those experiencing harms from heavy Internet use (Johnson, 2015). Instead, participants appeared to support a compensatory conceptualisation of technology- 
related problems (Kardefelt-Winther, 2014a). This was evidenced by observations that problems typically arose when individuals were experiencing other difficulties in their life and engaged with technology as a means of serving some type of unmet need. These observations are consistent with evidence suggesting that excessive technology use may indirectly influence psychosocial wellbeing by way of dysregulated emotional states and coping styles (Kardefelt-Winther, 2014b; Laier et al., 2018; Servidio et al., 2018; Weinstein et al., 2017; Wichstrom et al., 2019). A large meta-analysis of studies investigating Internet Addiction (IA) in the Korean population found that intra-personal difficulties (problems of the self) were more strongly associated with IA than were interpersonal difficulties (problems with others) (Koo \& Kwon, 2014). Similarly, longitudinal studies suggest that excessive gaming does not appear to result in long-term detrimental health consequences by itself; and that having one's needs for competence, autonomy, and self-efficacy met may act as a protective buffer against problems (Latinsky \& Ueno, 2021; Weinstein et al., 2017).

Youth experiencing socioeconomic disadvantage or poor parental care/relationships were purported by participants as more inclined to develop problems with technology; whereas those with adequate social support, family life, and peer relationships were described as more resilient to problems. Consistent with participants' observations, there is evidence that parental relationships and family dynamics play an important role in the development of technology-related problems for young people (Shek et al., 2018; Siomos et al., 2012; Venkatesh et al., 2019). It should be noted that although problematic levels of technology use tend to be associated with comorbid mental health and psychosocial difficulties, moderate engagement appears to represent a marker for normal development and may be associated with better health outcomes than no engagement (Latinsky \& Ueno, 2021). The non-linear relationship between technology use and harms has been described as a 'rich getting richer' and 'poor getting poorer' phenomenon whereby individuals already experiencing disadvantage are most likely to experience problems and those prospering tend to capitalise on its advantages (Kraut et al., 2002; Latinsky \& Ueno, 2021).

Such empirical studies, along with observations from the current study, suggest internal psychological difficulties and social disadvantage play important roles in development of technology-related problems. Future research on technology-related problems may benefit from conceptualising problems by considering the interaction between technology and psychosocial factors using mediational and interaction methodologies, rather than direct causal models (Kardefelt-Winther, 2014a).

\section{Identifying Technology-Related Problems}

Consistent with previous literature, participants reported young men were more likely to experience problems with gaming (Király et al., 2017; Wartberg et al., 2019; Wichstrom et al., 2019) and young women were more likely to experience problems with social media (Booker, 2019; Twigg et al., 2020). For many participants, further perspectives on vulnerable populations were mixed and predominantly speculative. Psychologists' represented one exception and seemed confident in identifying more specific subgroups of problematic technology users. Psychologists described children with Autistic Spectrum Disorder (ASD) symptoms (particularly males) and those with Borderline Personality Disorder (BPD) symptoms (particularly females) as especially vulnerable populations for video gaming and social media-related problems, respectively. While generalisation should be cautioned, there is a small amount of evidence suggesting individuals with ASD symptoms are more prone to gaming problems (MacMullin et al., 2016; Mazurek \& Engelhardt, 2013; Mazurek \& Wenstrup, 2013). However, it should not be assumed that this relationship operates bi-directionally, most people who play video games do not have social difficulties akin to those with ASD (Latinsky \& Ueno, 2021).

Gambling was only mentioned by a small number of participants and it did not appear to constitute a significant proportion of youth seeking help through mental health services. This is somewhat surprising given that young adults constitute one of the most at-risk groups for gambling problems (Nowak \& Aloe, 2014) and that young people are overrepresented in the online gambling market (Gambling Commission, 2019). There is considerable stigma associated with gambling disorder which may contribute to the large time lag between onset of problems and later help-seeking (Hing et al., 2016). One possible explanation is that young people are not presenting with gambling problems to these services due to a lack of problem awareness and associated social stigma. 
Many participants stated that they would benefit from more training in technology-related problems so that they could improve their awareness of potential problems and existing referral options. Given that many community and education services operate on strict often government-funded budgets, it may be more appropriate to target screening questions toward subgroups of young people who are at an increased risk of experiencing particular types of technology-related problems (e.g., young men engaging in high-levels of gaming and young women engaging excessively with social media). Psychometric scales to measure problematic gaming, gambling, internet use, social media use, and smartphone use have been developed. However, for parsimony, it may be more appropriate that community and educational organisations include broad questions about excessive technology use in general as part of routine assessment, and probe further with screening measures for specific activities when initial signs of problems have been identified. Many organisations represented in the current study appear to do this well, and use their expertise building rapport with young people to elicit this type of information. Having a formalised screening question for broad technology use may assist professionals working with young people to acquire this information more systematically.

It would also be beneficial for quantitative studies to investigate the visibility of technology-related problems, relative to other mental health problems. For example, from an addiction framework, it would be of value to know how many young people seek treatment for problems associated with digital devices compared to substance use problems. Such a comparison would provide important insights into the scope of the problem and existing gaps in treatment services.

\section{Limitations}

The findings of the current study were not intended to be representative of all youth professionals, young people, or use of online activities and digital devices, and care should be taken not to generalise the thoughts and opinions of our sample to all service providers or young adults. Despite clear instructions, participants often broadened the discussion to encompass different age groups such as adolescents and children, as well as other negative consequences not necessarily relating to one's mental health (physical, social and educational difficulties). We anticipated some creep due to the mixed deductive/inductive research methodology, and care was taken during the analysis to represent all sentiments fairly in the final results. Finally, because participants largely represented an older generation to the target age group $\left(M_{\text {age }}=39.29\right)$ it is not clear if perceptions of youth's level of engagement with technology can be accurately conceptualised as problematic, or if such levels were merely higher than participants', emphasising key differences in intergenerational developmental experiences. This was evidenced by many participants comparing their childhood with that of participants, often biased toward their own nostalgic experiences (e.g., "Back in my day..."). Older generations have been criticised for contributing to moral panic about young people's use of novel technological innovations (Bowman, 2017).

\section{Implications and Conclusion}

The current study results provide some insight into observations of harm, and potential perspectives and gaps in service provision with regards to technology-related problems amongst young people. There are no consistent formal screening or data collection processes for technology-related problems among [blinded city]-based community, educational, and mental health services. Youth services did not appear to have the available resources necessary to identify and assist with technology-related problems, despite interest in upskilling staff and organisational processes. Without clear data collection procedures, it is difficult to determine the level of harm associated with technology-related problems in the community, and its relative impact on society. Several focus group participants suggested that education for youth professionals may be an effective means of increasing early identification of those who are likely to experience technology-related harms.

Most of the technology-related problems that focus group participants observed related to young people's social and emotional wellbeing, including feelings of social isolation and unhealthy beliefs about social expectations. In line with previous literature, participants' conceptualisation of technology-related problems represented a complex interplay between social disadvantage and psychological vulnerabilities. Given that mental health problems peak during early adulthood, young people may be at greater risk for technology-related problems during this time. 
General 'life skills' prevention strategies which focus on improving problem-solving, critical thinking, and resisting peer-pressure may be appropriate for technology-related problems (Throuvala et al., 2019). However, studies investigating the efficacy of these types of interventions for alcohol, drug, and gambling behaviour have returned mixed results, and are often confounded by a lack of clear control comparison groups clarifying the unique contribution of the life skills component compared to more specific problem-behaviour education (e.g., Botvin \& Griffin, 2004; Luna-Adame et al., 2013; Lupu \& Lupu, 2013; Todirita \& Lupu, 2013).

Moreover, young adults currently seeking assistance through community organisations such as homelessness, welfare, or family services are likely already experiencing disadvantage and therefore may represent a higher risk group for technology-related problems. For these reasons, it may be appropriate for mental health professionals to include conversations around healthy technology use with young people who are already experiencing mental health problems or seeking assistance through community health and welfare organisations. A formal screening question asking young people about their technology use may help to determine who may benefit from further specific technology-related problem screening measures.

This study provides a meaningful contribution to the field of technology-related harms by providing insights into community and health care professionals' observations of youth-technology interactions including its potential harms and gaps in assessment and available help services. It provides recommendations on how to improve screening in the community and may help to raise awareness of particular youth profiles who are more likely to experience distress and/or harms from engaging in excessive and problematic technology use.

\section{References}

American Psychiatric Association. (2013). Diagnostic and statistical manual of mental disorders: DSM-5 ${ }^{\mathrm{TM}}$ (5th ed.). American Psychiatric Publishing.

Australian Bureau of Statistics. (2018). Household use of information technology, Australia, 2016-17 (Report No. 8146.0). https://www.abs.gov.au/ausstats/abs@.nsf/mf/8146.0

Baggio, S., Starcevic, V., Studer, J., Simon, O., Gainsbury, S. M., Gmel, G., \& Billieux, J. (2018). Technology-mediated addictive behaviors constitute a spectrum of related yet distinct conditions: A network perspective. Psychology of Addictive Behaviors, 32(5), 564-572. https://doi.org/10.1037/adb0000379

Boers, E., Afzali, M. H., Newton, N., \& Conrod, P. (2019). Association of screen time and depression in adolescence. JAMA Pediatrics, 173(9), 853-859. https://doi.org/10.1001/jamapediatrics.2019.1759

Booker, J. (2019, September 24). Why casinos are being forced to make skill-based slots. Best U.S. Casinos. https://www.bestuscasinos.org/blog/casino-skill-based-slot-machines/

Botvin, G. J., \& Griffin, K. W. (2004). Life skills training: Empirical findings and future directions. Journal of Primary Prevention, 25(2), 211-232. https://doi.org/10.1023/B:JOPP.0000042391.58573.5b

Bowman, N. (2017). Banning smartphones for kids is just another technology-fearing moral panic. The Conversation. http://theconversation.com/banning-smartphones-for-kids-is-just-another-technology-fearingmoral-panic-74485

Brand, J. E., Todhunter, S., \& Jervis, J. (2017). Digital Australia 2018. Interactive Games \& Entertainment Association. https://www.igea.net/wp-content/uploads/2017/07/Digital-Australia-2018-DA18-Final-1.pdf

Brand, M., Laier, C., \& Young, K. S. (2014). Internet addiction: Coping styles, expectancies, and treatment implications. Frontiers in Psychology, 5, Article 1256. https://doi.org/10.3389/fpsyg.2014.01256

Buntin, M. B., Burke, M. F., Hoaglin, M. C., \& Blumenthal, D. (2011). The benefits of health information technology: A review of the recent literature shows predominantly positive results. Health Affairs, 30(3), 464-471. https://doi.org/10.1377/hlthaff.2011.0178 
Busch, P. A., \& McCarthy, S. (2021). Antecedents and consequences of problematic smartphone use: A systematic literature review of an emerging research area. Computers in Human Behavior, 114, Article 106414.

https://doi.org/10.1016/j.chb.2020.106414

Dong, G., \& Potenza, M. N. (2014). A cognitive-behavioral model of Internet gaming disorder: Theoretical underpinnings and clinical implications. Journal of Psychiatric Research, 58, 7-11.

https://doi.org/10.1016/j.jpsychires.2014.07.005

Echazu, L., \& Nocetti, D. (2019). Understanding risky behaviors during adolescence: A model of self-discovery through experimentation. International Review of Law and Economics, 57, 12-21.

https://doi.org/10.1016/j.irle.2018.11.001

Fam, J. Y. (2018). Prevalence of Internet gaming disorder in adolescents: A meta-analysis across three decades. Scandinavian Journal of Psychology, 59(5), 524-531. https://doi.org/10.1111/sjop.12459

Gainsbury, S. M., King, D. L., Russell, A. M. T., \& Delfabbro, P. (2016). Who pays to play freemium games? The profiles and motivations of players who make purchases within social casino games. Journal of Behavioral Addictions, 5(2), 221-230. https://doi.org/10.1556/2006.5.2016.031

Gambling Commission. (2019). Gambling participation in 2018: Behaviour, awareness and attitudes. https://www.gamblingcommission.gov.uk/PDF/survey-data/Gambling-participation-in-2018-behaviourawareness-and-attitudes.pdf

Goldzweig, C. L., Towfigh, A., Maglione, M., \& Shekelle, P. G. (2009). Costs and benefits of health information technology: New trends from the literature. Health Affairs, 28(Suppl. 2), w282-w293.

https://doi.org/10.1377/hlthaff.28.2.w282

González-Bueso, V., Santamaría, J. J., Fernández, D., Merino, L., Montero, E., Jiménez-Murcia, S., del PinoGutiérrez, A., \& Ribas, J. (2018). Internet gaming disorder in adolescents: Personality, psychopathology and evaluation of a psychological intervention combined with parent psychoeducation. Frontiers in Psychology, 9, Article 787. https://doi.org/10.3389/fpsyg.2018.00787

Grant, J. E., Potenza, M. N., Weinstein, A., \& Gorelick, D. A. (2010). Introduction to behavioral addictions. The American Journal of Drug and Alcohol Abuse, 36(5), 233-241. https://doi.org/10.3109/00952990.2010.491884

Hing, N., Nuske, E., Gainsbury, S. M., Russell, A. M. T., \& Breen, H. (2016). How does the stigma of problem gambling influence help-seeking, treatment and recovery? A view from the counselling sector. International Gambling Studies, 16(2), 263-280. https://doi.org/10.1080/14459795.2016.1171888

Ipsos MORI. (2011). Underage gambling in England and Wales: A research study among 11-16 year olds on behalf of the National Lottery Commission. National Lottery Commission.

Johnson, N. F. (2015). Arguing the need for qualitative exploration in the field of emerging digital pathologies. Studia Psychologica, 15(2), 123-137. https://doi.org/10.21697/sp.2015.14.2.08

Kardefelt-Winther, D. (2014a). A conceptual and methodological critique of internet addiction research: Towards a model of compensatory internet use. Computers in Human Behavior, 31, 351-354.

https://doi.org/10.1016/j.chb.2013.10.059

Kardefelt-Winther, D. (2014b). The moderating role of psychosocial well-being on the relationship between escapism and excessive online gaming. Computers in Human Behavior, 38, 68-74.

https://doi.org/10.1016/j.chb.2014.05.020

Keen, B. (2019). Using misconceptions to improve engagement and preventative effects within gambling education [Doctoral thesis, The University of Sydney]. Sydney Digital Theses. http://hdl.handle.net/2123/21190 
Keles, B., McCrae, N., \& Grealish, A. (2020). A systematic review: The influence of social media on depression, anxiety and psychological distress in adolescents. International Journal of Adolescence and Youth, 25(1), 79-93. https://doi.org/10.1080/02673843.2019.1590851

Kessler, R. C., Amminger, G. P., Aguilar-Gaxiola, S., Alonso, J., Lee, S., \& Üstün, T. B. (2007). Age of onset of mental disorders: A review of recent literature. Current Opinion in Psychiatry, 20(4), 359-364.

https://doi.org/10.1097/YCO.0b013e32816ebc8c

King, D. L., \& Delfabbro, P. H. (2014). The cognitive psychology of Internet gaming disorder. Clinical Psychology Review, 34(4), 298-308. https://doi.org/10.1016/j.cpr.2014.03.006

King, D. L., \& Delfabbro, P. H. (2019). Internet gaming disorder: Theory, assessment, treatment, and prevention. Academic Press. https://doi.org/10.1016/C2016-0-04107-4

King, D. L., Delfabbro, P. H., \& Griffiths, M. D. (2012). Clinical interventions for technology-based problems: Excessive Internet and video game use. Journal of Cognitive Psychotherapy, 26(1), 43-56.

https://doi.org/10.1891/0889-8391.26.1.43

King, D. L., Delfabbro, P. H., Kaptsis, D., \& Zwaans, T. (2014). Adolescent simulated gambling via digital and social media: An emerging problem. Computers in Human Behavior, 31, 305-313.

https://doi.org/10.1016/j.chb.2013.10.048

King, D. L., Delfabbro, P. H., Zwaans, T., \& Kaptsis, D. (2013). Clinical features and axis I comorbidity of Australian adolescent pathological Internet and video game users. Australian \& New Zealand Journal of Psychiatry, 47(11), 1058-1067. https://doi.org/10.1177/0004867413491159

Király, O., Sleczka, P., Pontes, H. M., Urbán, R., Griffiths, M. D., \& Demetrovics, Z. (2017). Validation of the TenItem Internet Gaming Disorder Test (IGDT-10) and evaluation of the nine DSM-5 Internet Gaming Disorder criteria. Addictive Behaviors, 64, 253-260. https://doi.org/10.1016/j.addbeh.2015.11.005

Koo, H. J., \& Kwon, J.-H. (2014). Risk and protective factors of Internet addiction: A meta-analysis of empirical studies in Korea. Yonsei Medical Journal, 55(6), 1691-1711. https://doi.org/10.3349/ymj.2014.55.6.1691

Kraut, R., Kiesler, S., Boneva, B., Cummings, J., Helgeson, V., \& Crawford, A. (2002). Internet paradox revisited. Journal of Social Issues, 58(1), 49-74. https://doi.org/10.1111/1540-4560.00248

Kremer, P., Elshaug, C., Leslie, E., Toumbourou, J. W., Patton, G. C., \& Williams, J. (2014). Physical activity, leisuretime screen use and depression among children and young adolescents. Journal of Science and Medicine in Sport, 17(2), 183-187. https://doi.org/10.1016/j.jsams.2013.03.012

Kuss, D. J., \& Griffiths, M. D. (2011). Online social networking and addiction-A review of the psychological literature. International Journal of Environmental Research and Public Health, 8(9), 3528-3552.

https://doi.org/10.3390/ijerph8093528

Kuss, D. J., Griffiths, M. D., Karila, L., \& Billieux, J. (2014). Internet addiction: A systematic review of epidemiological research for the last decade. Current Pharmaceutical Design, 20(25), 4026-4052. https://doi.org/10.2174/13816128113199990617

Laier, C., Wegmann, E., \& Brand, M. (2018). Personality and cognition in gamers: Avoidance expectancies mediate the relationship between maladaptive personality traits and symptoms of Internet-gaming disorder. Frontiers in Psychiatry, 9, Article 304. https://doi.org/10.3389/fpsyt.2018.00304

Latinsky, A., \& Ueno, K. (2021). Leveling up? Video game play in adolescence and the transition into adulthood. The Sociological Quarterly, 62(1), 36-59. https://doi.org/10.1080/00380253.2019.1711265 
Loh, A. H. Y., Ooi, Y. P., Lim, C. G., Fung, S. S. D., \& Khoo, A. (2016). Managing adolescents with gaming problems: The Singapore counsellors' perspective. International Journal of Psychology and Behavioral Sciences, 6(1), 7-13. http://article.sapub.org/10.5923.j.ijpbs.20160601.02.html

Lorains, F. K., Cowlishaw, S., \& Thomas, S. A. (2011). Prevalence of comorbid disorders in problem and pathological gambling: Systematic review and meta-analysis of population surveys. Addiction, 106(3), 490-498. https://doi.org/10.1111/j.1360-0443.2010.03300.x

Luna-Adame, M., Carrasco-Giménez, T. J., \& Rueda-García, M. M. (2013). Evaluation of the effectiveness of a smoking prevention program based on the 'Life Skills Training' approach. Health Education Research, 28(4), 673682. https://doi.org/10.1093/her/cyt061

Lupu, I. R., \& Lupu, V. (2013). Gambling prevention program for teenagers. Journal of Cognitive and Behavioral Psychotherapies, 13(2a), 575-584. http://jebp.psychotherapy.ro/vol-xiii-special-issue-2a-2013/gamblingprevention-program-teenagers/

MacMullin, J. A., Lunsky, Y., \& Weiss, J. A. (2016). Plugged in: Electronics use in youth and young adults with autism spectrum disorder. Autism, 20(1), 45-54. https://doi.org/10.1177/1362361314566047

Maras, D., Flament, M. F., Murray, M., Buchholz, A., Henderson, K. A., Obeid, N., \& Goldfield, G. S. (2015). Screen time is associated with depression and anxiety in Canadian youth. Preventive Medicine, 73, 133-138.

https://doi.org/10.1016/j.ypmed.2015.01.029

Mazurek, M. O., \& Engelhardt, C. R. (2013). Video game use in boys with autism spectrum disorder, ADHD, or typical development. Pediatrics, 132(2), 260-266. https://doi.org/10.1542/peds.2012-3956

Mazurek, M. O., \& Wenstrup, C. (2013). Television, video game and social media use among children with ASD and typically developing siblings. Journal of Autism and Developmental Disorders, 43(6), 1258-1271. https://doi.org/10.1007/s10803-012-1659-9

McNicol, M. L., \& Thorsteinsson, E. B. (2017). Internet addiction, psychological distress, and coping responses among adolescents and adults. Cyberpsychology, Behavior and Social Networking, 20(5), 296-304. https://doi.org/10.1089/cyber.2016.0669

Mentzoni, R. A., Brunborg, G. S., Molde, H., Myrseth, H., Skouverøe, K. J. M., Hetland, J., \& Pallesen, S. (2011). Problematic video game use: Estimated prevalence and associations with mental and physical health. Cyberpsychology, Behavior and Social Networking, 14(10), 591-596. https://doi.org/10.1089/cyber.2010.0260

Mitchell, M. E., Lebow, J. R., Uribe, R., Grathouse, H., \& Shoger, W. (2011). Internet use, happiness, social support and introversion: A more fine grained analysis of person variables and internet activity. Computers in Human Behavior, 27(5), 1857-1861. https://doi.org/10.1016/j.chb.2011.04.008

Nowak, D. E., \& Aloe, A. M. (2014). The prevalence of pathological gambling among college students: A metaanalytic synthesis, 2005-2013. Journal of Gambling Studies, 30(4), 819-843. https://doi.org/10.1007/s10899-0139399-0

Pascoe, M., Bailey, A. P., Craike, M., Carter, T., Patten, R., Stepto, N., \& Parker, A. (2020). Physical activity and exercise in youth mental health promotion: A scoping review. BMJ Open Sport \& Exercise Medicine, 6(1), Article e000677. https://doi.org/10.1136/bmjsem-2019-000677

Petry, N. M., Zajac, K., \& Ginley, M. K. (2018). Behavioral addictions as mental disorders: To be or not to be? Annual Review of Clinical Psychology, 14, 399-423. https://doi.org/10.1146/annurev-clinpsy-032816-045120

Pittman, M., \& Reich, B. (2016). Social media and loneliness: Why an Instagram picture may be worth more than a thousand Twitter words. Computers in Human Behavior, 62, 155-167. https://doi.org/10.1016/j.chb.2016.03.084 
Pontes, H. M. (2017). Investigating the differential effects of social networking site addiction and Internet gaming disorder on psychological health. Journal of Behavioral Addictions, 6(4), 601-610.

https://doi.org/10.1556/2006.6.2017.075

Pontes, H. M., \& Griffiths, M. D. (2017). The development and psychometric evaluation of the Internet Disorder Scale (IDS-15). Addictive Behaviors, 64, 261-268. https://doi.org/10.1016/j.addbeh.2015.09.003

Rehbein, F., Kliem, S., Baier, D., Mößle, T., \& Petry, N. M. (2015). Prevalence of internet gaming disorder in German adolescents: Diagnostic contribution of the nine DSM-5 criteria in a state-wide representative sample. Addiction, 110(5), 842-851. https://doi.org/10.1111/add.12849

Schreier, M. (2014). Qualitative content analysis. In U. Flick (Ed.), The SAGE Handbook of Qualitative Data Analysis (pp. 170-183). SAGE Publications, Inc. https://doi.org/10.4135/9781446282243.n12

Servidio, R., Gentile, A., \& Boca, S. (2018). The mediational role of coping strategies in the relationship between self-esteem and risk of Internet addiction. Europe's Journal of Psychology, 14(1), 176-187.

https://doi.org/10.5964/ejop.v14i1.1449

Shapira, N. A., Lessig, M. C., Goldsmith, T. D., Szabo, S. T., Lazoritz, M., Gold, M. S., \& Stein, D. J. (2003). Problematic internet use: Proposed classification and diagnostic criteria. Depression and Anxiety, 17(4), 207-216. https://doi.org/10.1002/da.10094

Shek, D. T. L., Zhu, X., \& Ma, C. M. S. (2018). The influence of parental control and parent-child relational qualities on adolescent internet addiction: A 3-year longitudinal study in Hong Kong. Frontiers in Psychology, 9, Article 642. https://doi.org/10.3389/fpsyg.2018.00642

Siomos, K., Floros, G., Fisoun, V., Evaggelia, D., Farkonas, N., Sergentani, E., Lamprou, M., \& Geroukalis, D. (2012). Evolution of Internet addiction in Greek adolescent students over a two-year period: The impact of parental bonding. European Child \& Adolescent Psychiatry, 21(4), 211-219. https://doi.org/10.1007/s00787-012-0254-0

Sohn, S. Y., Rees, P., Wildridge, B., Kalk, N. J., \& Carter, B. (2019). Prevalence of problematic smartphone usage and associated mental health outcomes amongst children and young people: A systematic review, meta-analysis and GRADE of the evidence. BMC Psychiatry, 19, Article 356. https://doi.org/10.1186/s12888-019-2350-x

Throuvala, M. A., Griffiths, M. D., Rennoldson, M., \& Kuss, D. J. (2019). School-based prevention for adolescent Internet addiction: Prevention is the key. A systematic literature review. Current Neuropharmacology, 17(6), 507525. https://doi.org/10.2174/1570159X16666180813153806

Todirita, I. R., \& Lupu, V. (2013). Gambling prevention program among children. Journal of Gambling Studies, 29(1), 161-169. https://doi.org/10.1007/s10899-012-9293-1

Torres-Rodríguez, A., Griffiths, M. D., \& Carbonell, X. (2018). The treatment of Internet gaming disorder: A brief overview of the PIPATIC program. International Journal of Mental Health and Addiction, 16(4), 1000-1015. https://doi.org/10.1007/s11469-017-9825-0

Twigg, L., Duncan, C., \& Weich, S. (2020). Is social media use associated with children's well-being? Results from the UK Household Longitudinal Study. Journal of Adolescence, 80, 73-83.

https://doi.org/10.1016/j.adolescence.2020.02.002

Valkenburg, P. M., Peter, J., \& Schouten, A. P. (2006). Friend networking sites and their relationship to adolescents' well-being and social self-esteem. CyberPsychology \& Behavior, 9(5), 584-590.

https://doi.org/10.1089/cpb.2006.9.584 
Venkatesh, V., Sykes, T. A., Chan, F. K. Y., Thong, J. Y. L., \& Hu, P. J.-H. (2019). Children's Internet addiction, familyto-work conflict, and job outcomes: A study of parent-child dyads. MIS Quarterly, 43(3), 903-927.

https://doi.org/10.25300/MISQ/2019/12338

Vernon, L. (2016). The role of problematic technology use for adolescents: The importance of sleep for wellbeing [Doctoral thesis, Murdoch University]. Murdoch University Research Repository.

https://researchrepository.murdoch.edu.au/id/eprint/35698/

Viera, A. J., \& Garrett, J. M. (2005). Understanding interobserver agreement: The kappa statistic. Family Medicine, $37(5), 360-363$.

Wartberg, L., Kriston, L., Zieglmeier, M., Lincoln, T., \& Kammerl, R. (2019). A longitudinal study on psychosocial causes and consequences of Internet gaming disorder in adolescence. Psychological Medicine, 49(2), 287-294. https://doi.org/10.1017/S003329171800082X

Weinstein, N., Przybylski, A. K., \& Murayama, K. (2017). A prospective study of the motivational and health dynamics of Internet Gaming Disorder. PeerJ, 5, Article e3838. https://doi.org/10.7717/peerj.3838

Wichstrøm, L., Stenseng, F., Belsky, J., von Soest, T., \& Hygen, B. W. (2019). Symptoms of Internet gaming disorder in youth: Predictors and comorbidity. Journal of Abnormal Child Psychology, 47(1), 71-83.

https://doi.org/10.1007/s10802-018-0422-x

World Health Organization. (2019a). 6C51 Gaming disorder. In International statistical classification of diseases and related health problems (11th ed.). https://icd.who.int/browse11/l-m/en\#/http://id.who.int/icd/entity/1448597234

World Health Organization. (2019b). Guidelines on physical activity, sedentary behaviour, and sleep for children under 5 years of age. http://www.ncbi.nlm.nih.gov/books/NBK541170/

Zenios, M., \& loannou, E. (2018). Digital natives and digital immigrants revisited: A case of CALL. In P. Zaphiris \& A. Ioannou (Eds.), Learning and collaboration technologies: Learning and teaching (pp. 99-110). Springer International Publishing. 


\section{Correspondence to:}

Brittany Keen

Gambling Treatment and Research Clinic

School of Psychology

The University of Sydney

NSW 2006

Australia

Email: Brittany.keen(at)live.com.au

Editorial record: First submission received on March 24, 2020. Revision received on November 10, 2020. Accepted for publication on February 8, 2021.

Editor in charge: Kristian Daneback

\section{About Authors}

Brittany Keen, PhD, conducted her PhD in gambling education among young people at the University of Sydney's Gambling Treatment and Research Clinic in Sydney, Australia. Dr Keen is currently working in research consultancy, focusing on community and healthcare decision-making.

Sally Gainsbury is Associate Professor, Director of the Gambling Treatment and Research Clinic and Leader of the Technology Addiction Team within the Brain and Mind Centre and School of Psychology at the University of Sydney. 